\title{
Mechanism of interaction between urbanization and resource environment in Central Asia
}

\author{
ZHANG Xinhuan $^{1,3}$, XU Wenqiang $^{1,2,3}$, XIANG Xinyi $^{4}$, ZHANG Zhiping ${ }^{1,3}$, \\ CUI Mingjie ${ }^{1,3}$
}

1. State Key Laboratory of Desert and Oasis Ecology, Xinjiang Institute of Ecology and Geography, CAS, Urumqi 830011, China;

2. Key Laboratory of GIS \& RS Application Xinjiang Uygur Autonomous Region, Urumqi 830011, China;

3. University of Chinese Academy of Sciences, Beijing 100049, China;

4. School of Geographical Sciences, Southwest University, Chongqing 400715, China

\begin{abstract}
Central Asia features an arid and semi-arid climate, and the region is undergoing urbanization in the context of a fragile eco-environment. The influence of specific historical events in this region also persists on this ongoing urbanization. This study examines the mechanism of interaction between urbanization and the resource environment in Central Asia. The following results were obtained. (1) In different periods-Russian colonization, the era of the Soviet Union, and Central Asian countries as independent-the interactions between urbanization and the resource environment varied. (2) Variations in land use within 50 $\mathrm{km}$ of major cities of the region reflect both the trend of urbanization and that of variations in the eco-environment. In Kyrgyzstan and Tajikistan, where urbanization has been slow, the supportive effect of the eco-environment for urbanization was clear. In Uzbekistan and Turkmenistan, where freshwater resources are scarce, a close relationship was noted between urbanization and variations in the eco-environment. In Kazakhstan, fast urbanization has had a significant impact on the availability of water, grassland, and woodland in the relevant areas. (3) The efficiency of utilization of land and water resources is generally low. The compactness of the urban land of 47 major cities in Central Asia decreased from 0.44 in 1990 to 0.31 in 2015 . Of them, 31 cities decreased in compactness, including all national capitals. Regardless of the level of urbanization, water consumption was high across the region. (4) The mechanisms of interaction between urbanization and the resource environment in Central Asia in the three stages were formulated to illustrate their specific temporal conductivity and spatial relevance.
\end{abstract}

Keywords: urbanization; resource environment; relation; Central Asia

Received: 2020-03-22 Accepted: 2020-08-03

Foundation: The Strategic Priority Research Program of Chinese Academy of Sciences, No.XDA20040402, No.XDA20030101

Author: Zhang Xinhuan (1978-), Associate Professor, specialized in sustainable development in arid regions.

E-mail: zhangxh@ms.xjb.ac.cn

"Corresponding author: Xu Wenqiang (1979-), Associate Professor, specializing in land use changes.

E-mail: xuwq@ms.xjb.ac.cn 


\section{Introduction}

Urbanization is the process of the non-agricultural transformation of population, industry, and land that has significant impacts on the regional environment. It has different effects on economic development and the resource environment at different scales (Cui et al., 2019). Therefore, the interaction between urbanization and the eco-environment is a focus of research across the world (Ma et al., 2018; Liu et al., 2019). In arid areas, this relationship is not only one of the interactive stresses, but also that of the mutual improvements (Qiao et al., 2005). Considering the shortage of water resources, the interactions between urbanization and the eco-environment in arid regions are complex and dramatic (Qiao et al., 2006). The progress of urbanization is affected significantly by different modes of utilization of water resources. Their overuse slows down urbanization (Bao et al., 2007). During urbanization, oases in the given area should be protected and allowed to flourish (Fang et al., 2003). There are three major issues in arid regions in the context of urbanization: the closure of oases and the flourishing of cities, scattered oases and concentrated cities, and ecological vulnerability and the pressures of human activities (Yang and Liu, 2014). It is important to coordinate urbanization with protection for the eco-environment for the sustainability of arid regions (Fang et al., 2019).

Central Asia is located at the center of Eurasia (Chen et al., 2016). With a temperate continental climate, the region is characterized by high evaporation and little rainfall, leading to a vulnerable ecosystem (Lioubimtseva and Henebry, 2009; Chen et al., 2013; He, 2016). The environment is threatened by freshwater shortage, water pollution, desertification, and salinization (Hu et al., 2018; Li et al., 2019). The geographical ecosystem is composed of mountains, oases, and deserts, which renders the natural backdrop to the urbanization of Central Asia extremely fragile. This has led to the extensive dispersion and localized concentration of cities and towns. The influence of Czarist Russia and the Soviet Union on the socio-economy of Central Asia has been significant, and continues to have an effect on its urban development. This study focuses on the relation between urbanization and the resource environment in Central Asia. A clear understanding of the process and mechanism of their interaction is necessary to determine appropriate means for the coordination and coexistence of human activities and the eco-environment in the future.

\section{Research area and method}

\subsection{Research area}

The study area was Central Asia consisting of five countries: Kazakhstan, Uzbekistan, Kyrgyzstan, Tajikistan, and Turkmenistan. It covers an area of $4.01 \times 10^{6} \mathrm{~km}^{2}$, ranging from $46^{\circ} 45^{\prime} 28.13^{\prime \prime}-87^{\circ} 21^{\prime} 47.81^{\prime \prime} \mathrm{E}$ to $35^{\circ} 5^{\prime} 2.24^{\prime \prime}-52^{\circ} 33^{\prime} 30.49^{\prime \prime} \mathrm{N}$ (Hu et al., 201). Mountains in the region are separated by valleys and basins. Numerous rivers and lakes have formed, and a large number of oases have developed in the plain alluvial fans, valleys, and basins. This has led to interactions among the mountains, oases, and deserts (Abuduwaili and Ma, 2015). The southeast mountainous area receives considerable precipitation, providing a water resource for the entire region. Based on statistics from 2004 published by the Food and Agriculture Organization of the United Nations, freshwater resources in the five countries 
amounted to $2213 \times 10^{8} \mathrm{~m}^{3}$, with an extremely uneven distribution owing to geological and geographical factors (Yao et al., 2013). Kazakhstan has the largest water resources in the region, accounting for $36.5 \%$, while Turkmenistan has the least, accounting for only $0.7 \%$ of the total (Deng et al., 2010).

Although Central Asia has a vast territory, space suitable for human habitation is limited. In 2017 , the total population of the region was 71.30 million, with a density of only 17.78 persons $/ \mathrm{km}^{2}$. It is distributed mainly in oases with rich water supply and lush vegetation, and in basins surrounded by high mountains. The gross domestic product (GDP) of the region is 265.20 billion US dollars (USD), accounting for only $0.33 \%$ of the world's GDP (Table 1 ). Although Central Asia's economic and social development is relatively low, yet it is a hub connecting East Asia, South Asia, the Middle East, and Europe. In particular since the collapse of the Soviet Union in 1991, the five Central Asian countries have become increasingly prominent in global geopolitics based on their special geographical location, rich mineral resources, and important ecological functions.

Table 1 Overview of the economic and social data for Central Asia (2017)

\begin{tabular}{lccccc}
\hline \multicolumn{1}{c}{ Country } & $\begin{array}{c}\text { Population } \\
\left(10^{3}\right)\end{array}$ & $\begin{array}{c}\text { Population density } \\
\left(\text { persons } / \mathrm{km}^{2}\right)\end{array}$ & $\begin{array}{c}\text { Urbanization rate } \\
(\%)\end{array}$ & $\begin{array}{c}\text { GDP } \\
\left(10^{6} \text { USD }\right)\end{array}$ & $\begin{array}{c}\text { GDP per capita } \\
(\text { USD })\end{array}$ \\
\hline Kazakhstan & 18037.78 & 6.68 & 57.34 & 162887 & 9030 \\
Uzbekistan & 32387.20 & 76.13 & 50.55 & 49677 & 1534 \\
Tajikistan & 8921.34 & 64.28 & 26.98 & 7146 & 801 \\
Turkmenistan & 5758.08 & 12.25 & 51.15 & 37926 & 6587 \\
Kyrgyzstan & 6198.20 & 32.32 & 36.14 & 7565 & 1220 \\
\hline
\end{tabular}

Data source: https://openknowledge.worldbank.org/

\subsection{Research method}

(1) Data sources

The national statistics data were taken from World Bank Open Data. Data on the population and water resources of the states of Kazakhstan were obtained from the Statistics of Kazakhstan since Independence (1991-2007) and the Kazakhstan Environmental Protection and Sustainable Development (2013-2017). The population data for states of Kyrgyzstan were obtained from the official website of the Kyrgyz National Statistical Commission, and the water resource data were taken from the Kyrgyzstan Yearbook of Environmental Statistics (2013-2017).

Landsat TM/OLI remote sensing images of the region from 1990 and 2015 were obtained from the website of the United States Geological Survey (USGS). Using ENVI 5.1, the data were preprocessed by false color synthesis and image mosaicking. The images were then preliminarily classified by using eCognition Developer 8.7 based on the sample classification method. Manual visual interpretation was then carried out combined with the empirical data. The land use types in the study area were classified into six categories: woodland, grassland, arable land, water body, urban and built-up land, and the Gobi desert. Using ArcGIS 10.2, the results of classification were calibrated and corrected, and their accuracy was tested. The accuracy of interpretation was 0.87 , which met the research requirements.

(2) Indicators 
The variation in land use index can reflect the extent and speed of certain types of land use in a period (Zhu and $\mathrm{Li}, 2003)$. It is expressed as follows:

$$
L V I_{i}=\frac{\left(L_{i, t}-L_{i, 0}\right)}{L_{i, 0}} \times 100 \%
$$

where $L V I_{i}$ is the expansion index of a certain kind of land from the beginning to the end of the research period, and $L_{i, 0}$ and $L_{i, t}$ are the land use areas at the beginning and the end of the research, respectively.

Urban land compactness is an indicator of spatial patch integrity and aggregation. Typically, the compactness index can indicate the trend of changes in the intensity of urban land use. Urban land compactness is expressed as follows:

$$
C=\frac{2 \sqrt{\pi A}}{P}
$$

where $C$ is urban land compactness, $A$ is the area of the built-up urban region, and $P$ is its perimeter. If the shape of the given area is close to round, the compactness index is close to one. If the surface features are widely scattered, the compactness index is a small value below one.

(3) Frame structure

The study focused on the relationship between urbanization and the resource environment in Central Asia. Using process-effect-mechanism as the tool for research, the work here can be divided into three parts. First, the interactions between urbanization and the resource environment in three stages are summarized. Second, the effects of urbanization on the resources and environment of major cities in Central Asia after independence were evaluated. Third, the mechanisms of interaction between them in different stages were obtained (Figure 1).

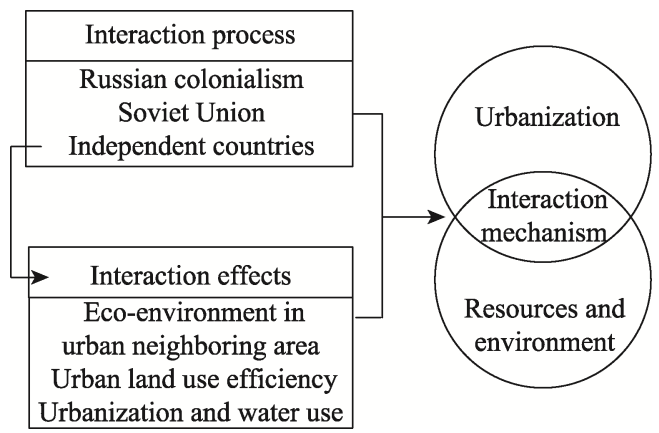

Figure 1 Frame of interactions between urbanization and the resource environment based on processeffect-mechanism

\section{Analysis and results}

\subsection{Process of interaction between urbanization and resource environment}

(1) Land conflicts attributed to urbanization during Russian colonialism

From the second half of the 19th century to the beginning of the 20th (1916), Central Asia was under Russian colonial rule. In 1861, Russia abolished serfdom and promoted a settlement policy. There were strong land drivers behind Russian colonial expansion that significantly changed the structure of land and population distribution in Central Asia. In the Ka- 
zakh steppe area, a vast expanse of the nomadic land was taken and distributed to the colonizers. In 1917, about 49.05 million ha of land was confiscated by Cossack colonizers, accounting for $20 \%$ of the current territory of Kazakhstan. This was used for the construction of fortresses, towns, and roads. The population of the Kazakh steppe in 1897 was 4,147,800, of which the Kazakh population accounted for $81 \%$. By 1914, its population had increased to $5,910,000$, of which the Kazakh population accounted for only $65.1 \%$. Russian colonists moved populations and built towns not only in the grasslands, but also in the desert fringes. At present, Russian-style buildings in urban housing can still be seen in farming areas (Adle $C, 2017)$. There was a clear pattern to the formation of new towns in the colonial period, and most were founded based on the locations of fortresses and the railway. Foundation construction led to the concentration of the colonists, and new settlements developed into towns in the process of the combination of the regional economy with the Russian economy.

Urbanization process in Grassland nomadic-Oasis settlement time was slow, which was accelerated significantly by both the rapidly increasing population and the newly constructed fortresses in Russian colonial process. Natural conditions were still the foundation for the formation of new towns as well as the development of existing cities and towns. Resource-related and environmental problems emerged due to the acceleration of urbanization. First, during colonization, a large number of small towns developed in the north of the Kazakh steppe for the construction of a military fortress line. In addition, arable land surrounding these towns invaded even high-quality grassland. The tension between colonial urbanization and the requirements of the local Kazakh herders for land were this unavoidable. Second, the colonial population was concentrated in Ferghana Valley, and the Syr Darya and Amu Darya Basins, where towns with a better natural environment had been settled for a long time. The rapid growth of population led to pressures on resources and the environment in these towns. Moreover, to meet the demand for cotton in the Russian market, Central Asia was converted into a large-scale cotton-planting area, and a massive amount of water was used. Thus, urbanization in this period began to impose pressures on resources and the environment, and grassland ecosystems were damaged by the development of arable and built-up land.

(2) Deterioration of resources and environment caused by passive urbanization in the Soviet Union

Land reform, agricultural collectivization, land reclamation, and industrial development promoted by the Soviet Union had a dramatic impact on the population, economy, and urbanization in Central Asia. Owing to the dual effects of immigration and a high birth rate, population growth was rapid. In 1985, the total population of Central Asia was 45.47 million, accounting for $16.4 \%$ of the population in the Soviet Union. In 1970 , it was only $2.9 \%$ of the total (Panov, 1985). Meanwhile, the growth in the urban population was remarkable and the rate of urbanization increased accordingly (IHSAS, 1997; Wuzhati, 2015). Industrialization was promoted in Central Asia by the Soviet government, and it became an important base for mining and industry. Existing industrial towns were developed further, and new mining towns and transportation hubs were gradually formed.

In this period, due to the promotion of the Soviet planned economy, the rapid but low-level urbanization and industrialization had a significant impact on the eco-environment in Central Asia. First, the rapid development of industrialization led to the depletion of cer- 
tain mineral resources. Serious environmental pollution also occurred in some industrial and mining towns. Second, the industrial and mining towns located in deserts suffered from low water resources. More seriously, large-scale land reclamation and the disorderly expansion of cotton fields in Central Asia began to meet the demands for food and raw cotton in the Soviet Union. In 1980, 95\% of raw cotton in the Soviet Union was produced in the Syr Darya and Amu Darya drainage basins. The unrestricted use of the two rivers has led to a sharp reduction in inflows into the Aral Sea. The Aral Sea crisis broke in this period as well, and the surrounding arable land and towns were all affected. Some towns decayed, and the system of resources and the environment supporting urbanization was significantly damaged.

(3) New problems of urbanization and resource environment faced by independent Central Asia

Before and after the dissolution of the Soviet Union, problems kept cropping up in the five countries, such as political emigration, decay of traditional industrial towns, collapse of public service systems, unemployment, and a lack of motivation for economic development. Only Uzbekistan showed a steadily growing trend of urbanization, whereas the other countries in Central Asia exhibited a platform period followed by slow growth and even decline (Figure 2).

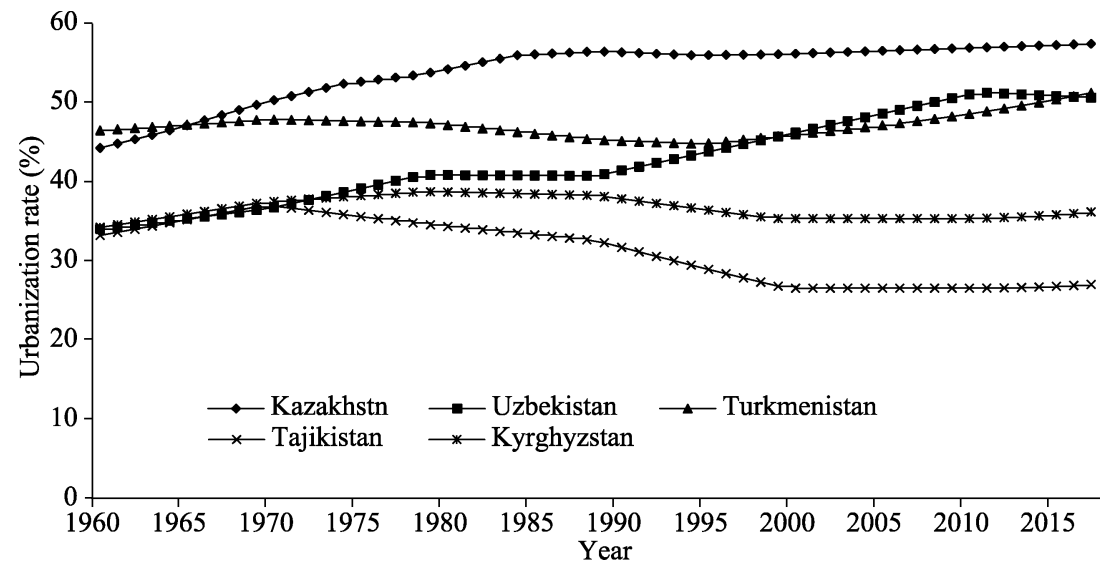

Figure 2 Trends of population urbanization in Central Asia (1960-2017)

In this stage, the urban area expanded rapidly and a large number of industrial zones were constructed, which exerted more pressure on the eco-environment. Numerous tensions arose, such as those between a decrease in water resources and an increase in water consumption, the upstream use and the downstream demand for water, and requirements of water for industrial, power generation-related, and irrigation-related uses. Central Asia is among the regions of the world most severely threatened by water shortage (Yang et al., 2017). In addition, due to 20 years of urbanization and industrialization, uncontrolled discharge of industrial wastewater and domestic sewage, and the large-scale use of chemical fertilizers and pesticides, a number of water bodies have been seriously polluted, watershed ecosystems have deteriorated, and the health of local people has been put at risk (Zhang, 2006). In many major cities, such as Astana and Almaty, standards for the concentration of pollutants, such as $\mathrm{PM}_{2.5}$ and $\mathrm{PM}_{10}$, have been severely exceeded (Xie et al., 2017). The eco-environment of 
Aral Sea continues to deteriorate. In response, the ecosystem of Central Asia has become more uncertain and complex.

In this period, due to the emergence of disputes over transnational water resources, the relation between urbanization and the eco-environment became increasingly complicated. On the one hand, the efficiency of utilization of water and land remained low. On the other hand, more water and land were needed to improve urban competitiveness. The transnational water disputes aggravated water-related risks to the urbanization of downstream countries, Uzbekistan and Turkmenistan, where this also put ecological and social security at risk.

\subsection{Effects of interactions between urbanization and resource environment}

(1) Ecological background of urbanization

Its land cover reflects the regional ecological background of urbanization in Central Asia. In 2015 , grasslands accounted for $29.68 \%$, arable land for $14.64 \%$, water bodies for $4.84 \%$, woodlands for $2.16 \%$, urban and built-up land for $1.06 \%$, and deserts accounted for $47.63 \%$ of total land.

We show the ecological background for urbanization of major cities under the buffer radius of $50 \mathrm{~km}$ (Figure 3). In general, most cities and the area of arable land were spatially interdependent at a certain scale while the area of arable land around some industrial towns was small. Kyrgyzstan, Tajikistan, and Kazakhstan are located in mountainous or hilly regions, with relatively small cities, and the areas of arable land and grassland around them are large. Some cities also feature water and woodlands in their neighborhood. Uzbekistan and Turkmenistan are located downstream of oases, and their cities are mainly surrounded by arable land, with a very small area of grassland. However, the cities in these two countries are relatively large. The ratio of desert land varies. In the neighborhood of major cities in Turkmenistan, the ratios of desert land range from $19 \%$ to $90 \%$, indicating the serious threats posed by desertification. Seven cities in the middle and western regions of Kazakhstan have desert land ranging in ratio from $21 \%$ to $78 \%$, and five cities downstream of Amu Darya in Uzbekistan have ratios of unutilized land ranging from $21 \%$ to $51 \%$, indicating

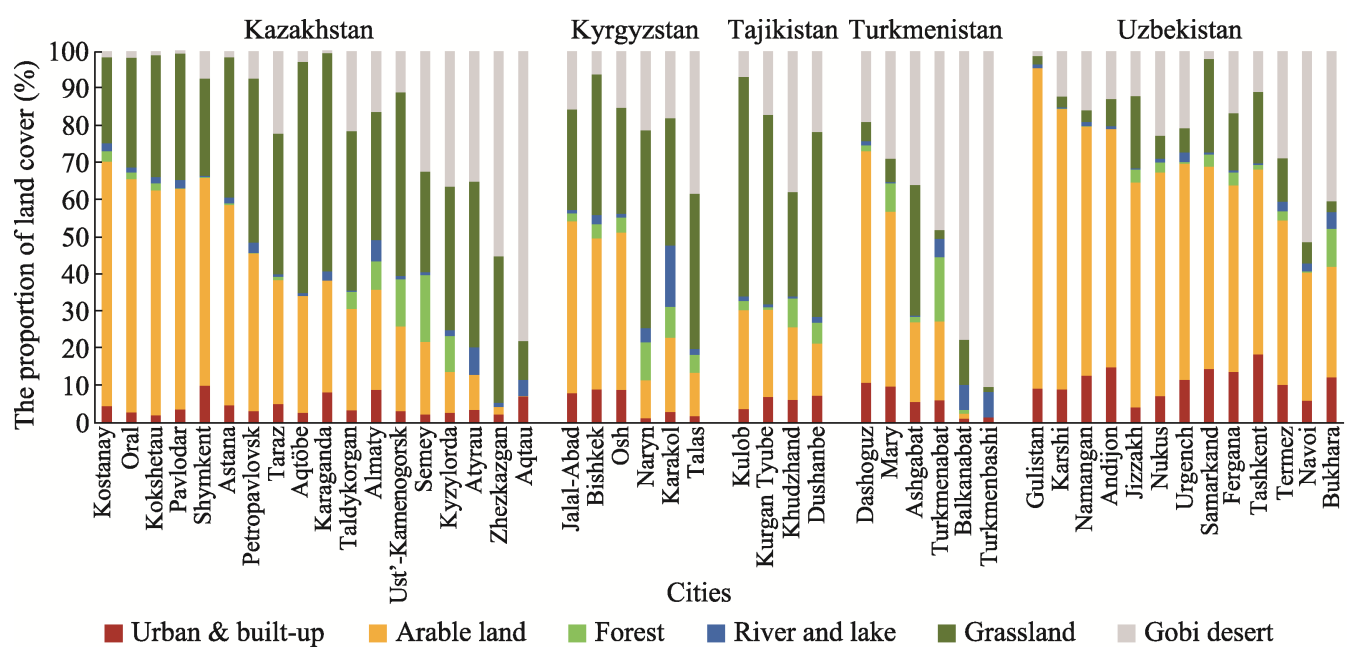

Figure 3 Land cover structure in the neighborhood of major cities in Central Asia (2015) Note: In 2019, the Kazakhstan capital Astana was renamed Nursultan. 
significant threats posed by desertification.

(2) Changes in ecological background in neighboring cities

Variations in land use in the $100 \mathrm{~km}$ circle of major cities can reflect both the trends of urbanization and the variation in the eco-environment. Variations in urban land reflects the trend of urbanization, that in arable land reflects the regional response to the available water resources, that in desert land reflects the threats posed by desertification, and the variations in grassland, woodland, and waters reflect the ecological background.

Kyrgyzstan and Tajikistan are mountainous countries, with similar trends of variation in land use in the major neighboring cities. Although urbanization has slowed down since 1990, the expansion of urban land is clear, especially in Tajikistan. Changes in arable and desert land were not significant, and the ratios of grassland, woodland, and water surfaces to the total land have remained constant. Owing to the slow urbanization, the supporting effect of the eco-environment is prominent (Figures $4 \mathrm{a}$ and $4 \mathrm{~b}$ ).

Uzbekistan and Turkmenistan are located downstream of the Amu Darya, and are characterized by typical oasis urbanization. A total of $63 \%$ of the cities have undergone a clear decrease in surrounding arable land, indicating the response of agriculture to the shortage of water resources. As most cities undergoing drastic expansion, those in Fergana Valley have had limited increases in urban land, indicating a constraint on urbanization. A clear decrease in water in the neighboring of towns in Turkmenistan has also been noted, further indicating the increasing pressure on cities downstream of the Amu Darya. (Figures 4c and 4d).

The process of urbanization in Kazakhstan can be divided into two types. For traditional industrial cities in the northeast and Aktau, the urban land expansion index was below 60\%, the surrounding arable land decreased in area because it was abandoned, desert land decreased significantly, but there was no clear change in woodland, grassland, and water. For industrial and mining cities in the west, and oases cities in the Syr Darya Basin, the expansion in urban land was drastic, arable land in oases was taken over by urbanization or abandoned, a large area of desert land was used to expand industrial and mining cities, and changes of waters and woodland were obvious. Urbanization with constant motivation exerted obvious impact on neighboring waters, grassland and woodland (Figures $4 \mathrm{e}$ and $4 \mathrm{f}$ ).

(3) Effect of expansion of land for urbanization

The area of urban land in Central Asia increased from $6413.86 \mathrm{~km}^{2}$ in 1990 to 9962.88 $\mathrm{km}^{2}$ in 2015 , with an average annual increase of $141.96 \mathrm{~km}^{2}$. The mode of urban land compactness decreased from 0.44 in 1990 to 0.31 in 2015, indicating the general decrease in the compactness of urban land and a disorderly urban sprawl. In this period, the urban land compactness of 47 cities of the region increased from 0.05 to 0.48 , of which those of 31 cities decreased, including the national capitals of all five countries (Figure 5). The low and decreasing urban land compactness values reflect the insignificant constraint posed by the area of available land on the process of urbanization in Central Asia. The process has clear urban expansionist features without the efficient use of land.

(4) Relationship between urbanization and water resources

An analysis of the relationship between the rate of urbanization, and water intake and the water consumption structure in every state of Kazakhstan and Kyrgyzstan can provide information on the relationship between urbanization and water resources. First, in states with 


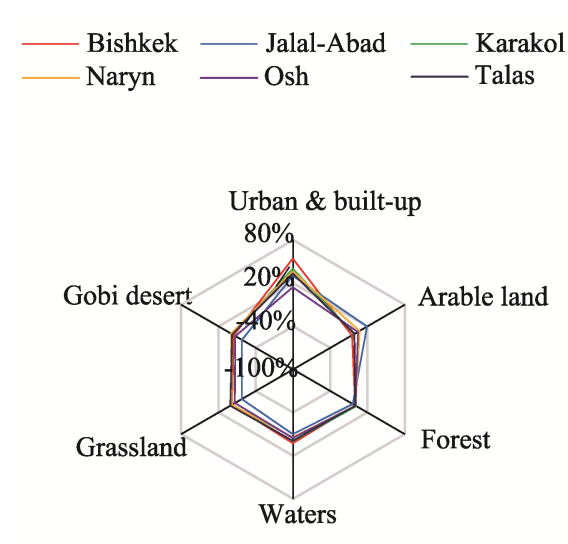

(a) Kyrgyzstan

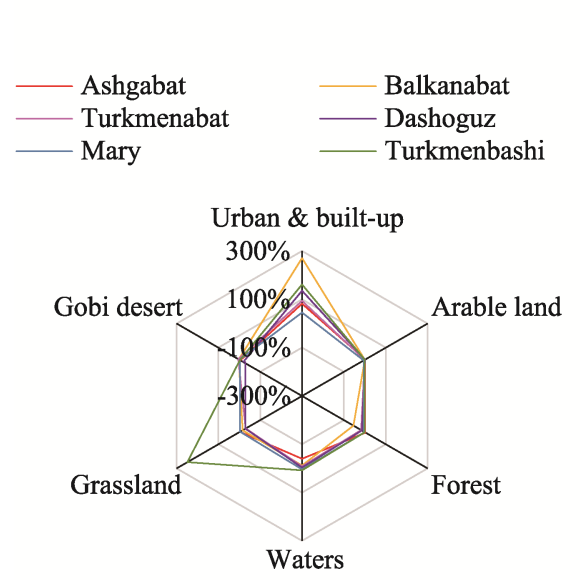

(c) Turkmenistan

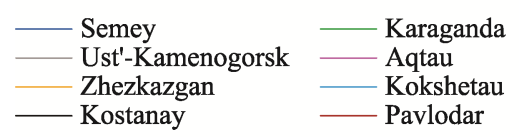

Urban \& built-up

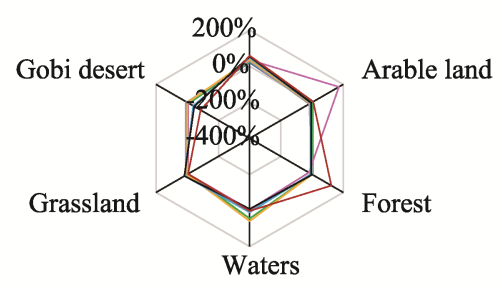

(e) Kazakhstan-1
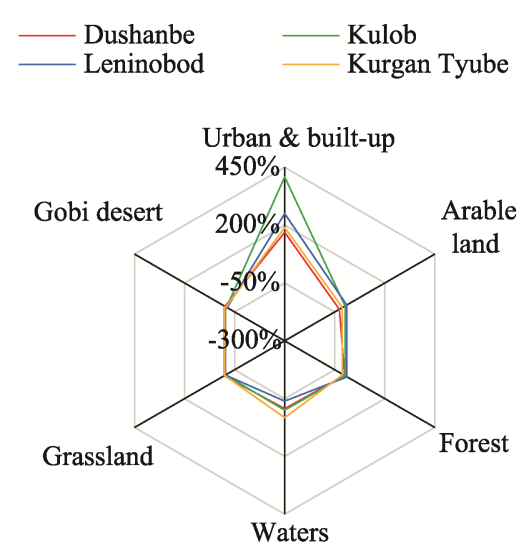

(b) Tajikistan
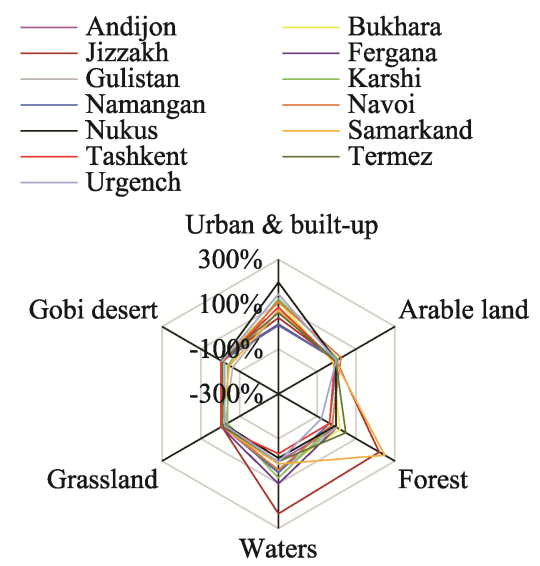

(d) Uzbekistan

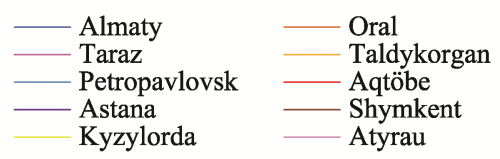

Urban \& built-up

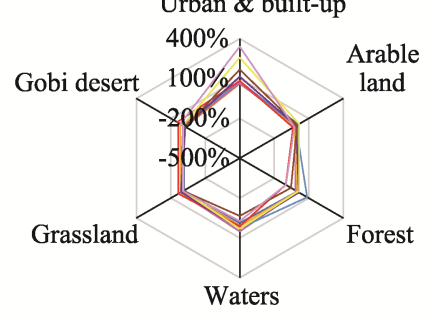

(f) Kazakhstan-2

Figure 4 Land use variation index in 100-km circle of major cities in Central Asia (1990-2015)

low urbanization rates, water intake was high (Figure 6), which can be attributed to the distribution of large-scale irrigation facilities for agriculture. Second, in states with comparatively high urbanization rates, the water consumption ratio for production was also high (Figure 7), indicating the effect of industrial development on urbanization. According to this, the rate of urbanization of every state was related to its water consumption structure to a 


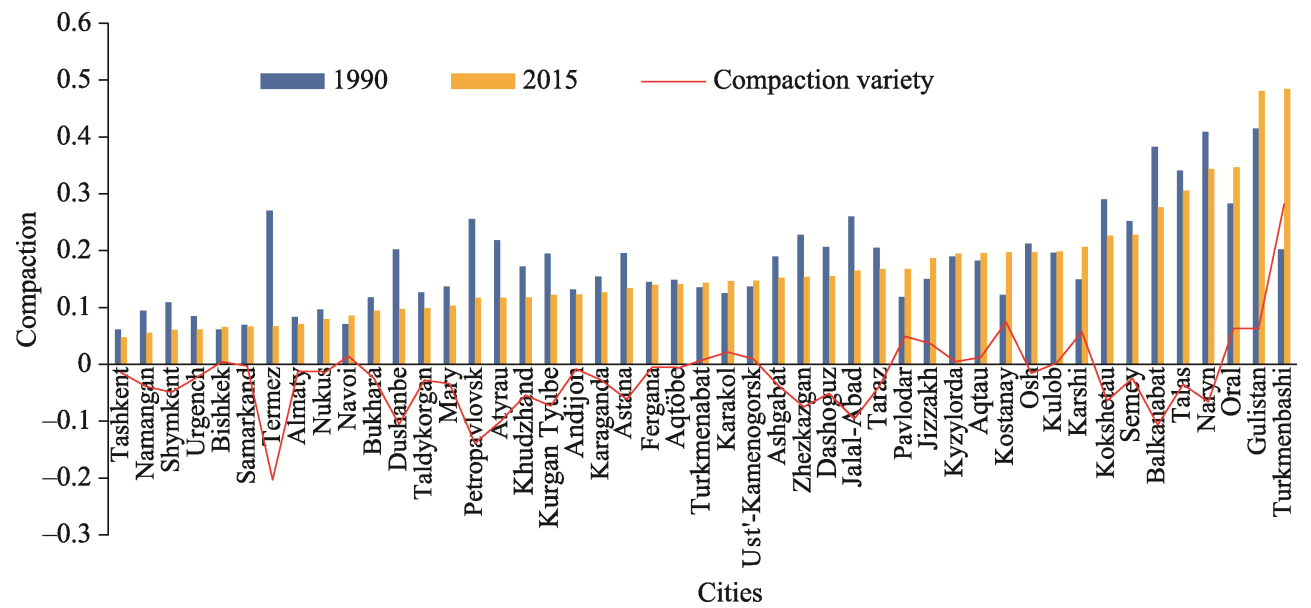

Figure 5 Variations in urban land compactness in 47 major cities

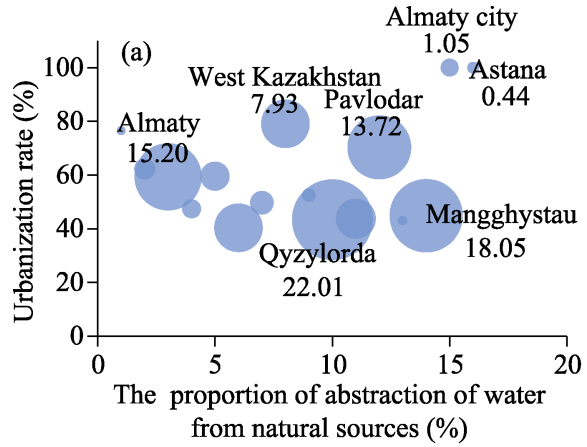

Kazakhstan

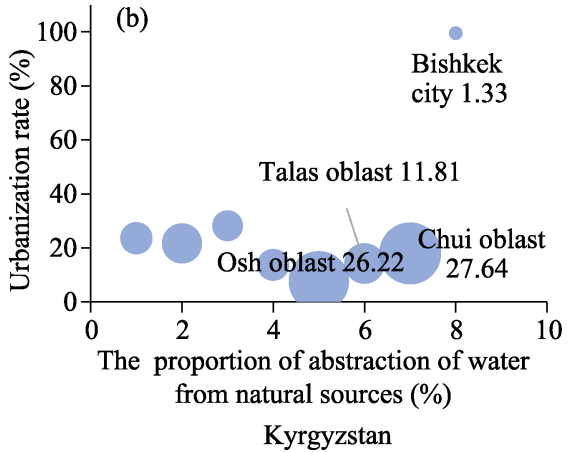

Bishkek

city 1.33

Figure 6 Relationship between urbanization rate and natural water intake in every state in Kazakhstan and Kyrgyzstan

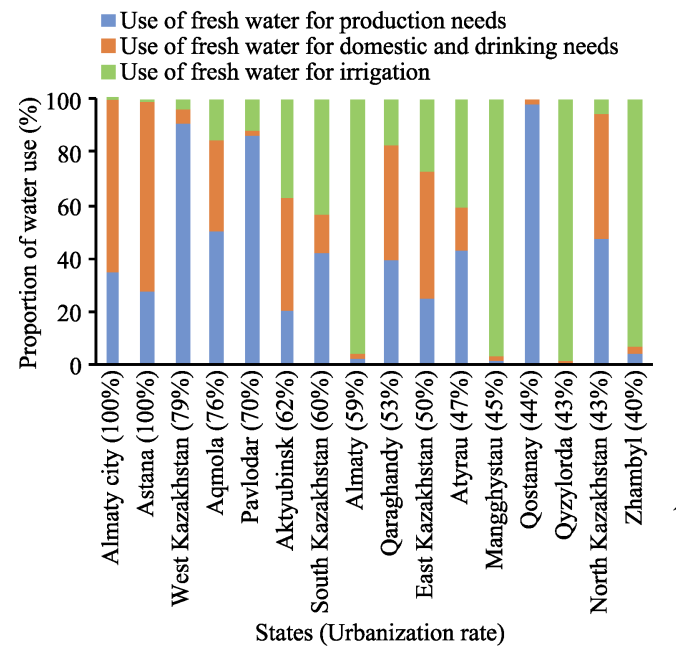

Kazakhstan

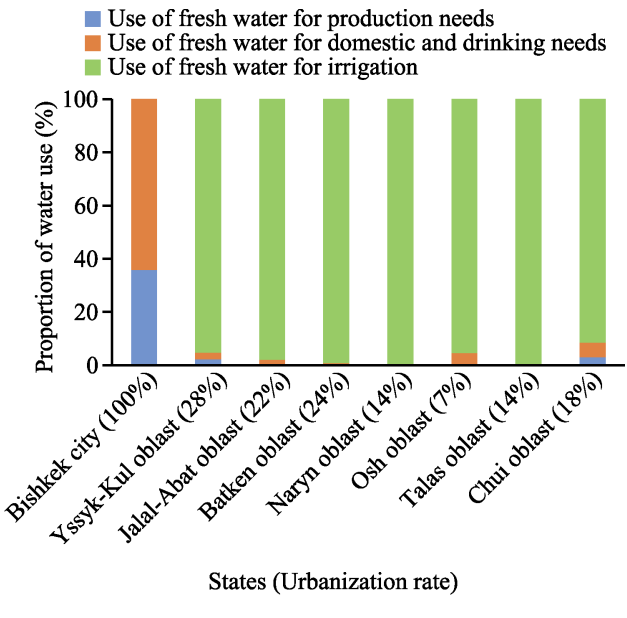

Kyrgyzstan

Figure 7 Relationship between urbanization rate and structure of water consumption in every state in Kazakhstan and Kyrgyzstan 
certain extent, but had little relation with the efficiency of utilization. Regardless of the level of urbanization, all states had consumed large amounts of water.

\subsection{Interaction between urbanization and resource environment}

\section{(1) Beginning of urbanization}

Before Russian colonization, most regions in Central Asia had a nomadic society. Seasonal migration made it difficult to form cities and towns in the grasslands and deserts to the north of Syr Darya, while for agricultural societies scattered in the oases and valleys, early cities and towns were developed in some khanate capitals (Figure 8a). Urbanization began in the Syr Darya and Amu Darya basins in Central Asia. The decisive natural condition for the emergence of cities and towns were oases beside river outflows, around lakes, or in valleys. Agriculture lands irrigated by rivers formed the ecological barrier between the city and the desert. Cities and towns developed adjacent to water, surrounded by and depending on the arable land. At the time, the pace of urbanization was stable and slow, water and land resources were abundant, and there was no conflict between urbanization and the available resources (Figure 9a).

(2) Period of passive acceleration of urbanization

Russian colonization and the planned economy of the Soviet Union changed the interaction between urbanization and the resource environment. The Kazakh steppe had been dominated by nomadic activities for a long time, and this changed under the impact of a large number of immigrants and the passive settlement of nomads. In this period, numerous fortress towns emerged along with traffic routes in the grasslands. In desert and mountain regions, industrial and mining towns emerged through the promotion of mining. Driven by strong external forces, towns developed on the basis of their mineral resources and exploitation of grassland. They extended from the oases to the deserts and grasslands. Although water was not the decisive factor for urban settlements, near-water features were prominent. With the water channels facilitating the expansion of agriculture land, the area occupied by urban land grew (Figure $8 \mathrm{~b}$ ). At this stage, the available

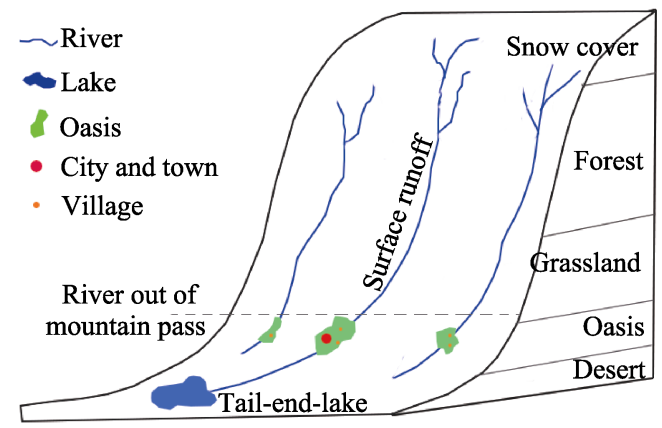

(a) Start-up stage of urbanization (1861-1916)

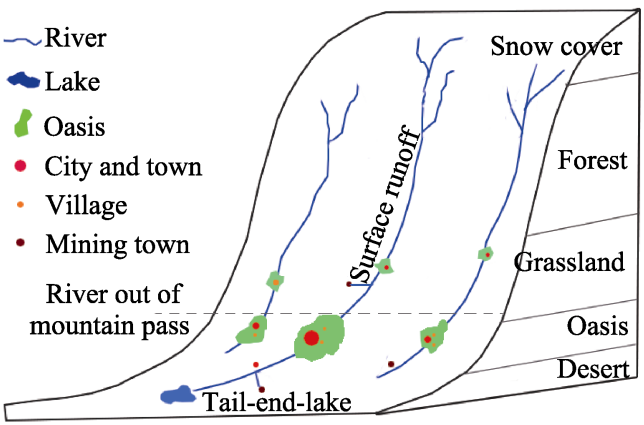

(b) Passive acceleration of urbanization (1917-1990)

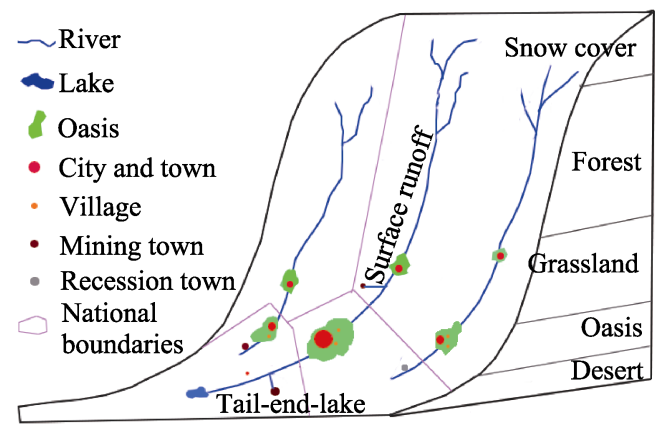

(c) Period of active development of urbanization

(1991-2017)

Figure 8 The spatial evolution of the relationship between urbanization and the resource environment in different periods in Central Asia (sketch map) 


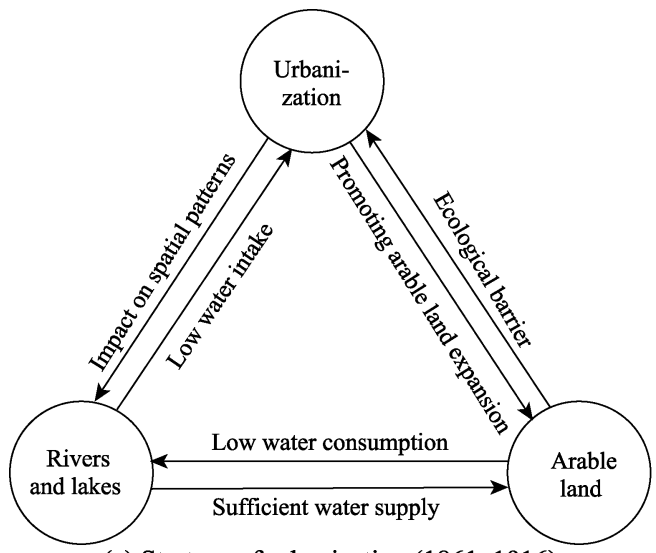

(a) Start-up of urbanization (1861-1916)

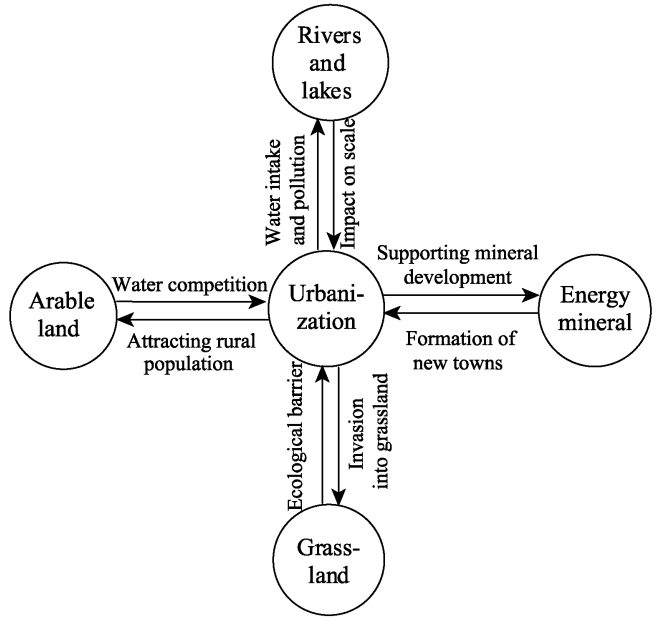

(b) Passive acceleration of urbanization (1917-1990)

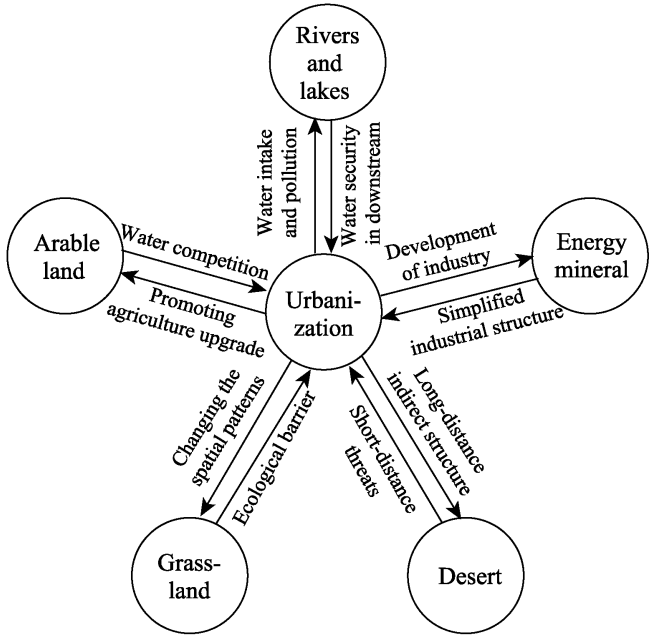

(c) Active development of urbanization (1991-2017)

Figure 9 Factors influencing the relationship between urbanization and the resource environment in different periods in Central Asia resources and the environment still reliably supported the excessively rapid urbanization, albeit with the emerging pressures from such natural factors as waters, grasslands, and minerals. The rapid expansion of urban and arable land changed the natural ecological pattern of grasslands and hydrology. Extensive mining led to a significant rise in waste in the environment (Figure 9b).

(3) Period of active development of urbanization

After the period of economic and social stagnation following the independence of Central Asia from the Soviet Union, the relationships between urbanization and resources, and the environment and the ecology became more complicated. Arable land, once the ecological barrier surrounding urban areas, was turned into grassland or abandoned land, and shrank drastically in area (Shi, 2009). The urbanization of industrial and mining towns in the north slowed down, while that in oases increased continually. For many towns, the driving force for urbanization was powerful, whereas for others, subjected to the pressures of limited water resources, exploitation of mineral resources, and threatened ecology, urbanization slowed further (Figure 8c). Due to the lack of development of environmental technology and investment, water pollution increased due to urbanization. Transnational water resource disputes also put the downstream countries of the Syr Darya and Amu Darya basins at risk of water shortage. The expansion of urban land was mostly uncontrolled. The effects of mining for energy and natural resources were unstable, and led to the rapid development of some mining towns and the decay of others. Low-level industrial and mining-related development led to significant water, air, and land pollution. Desertification has brought about the decay of adjacent cities and towns. Urbanization has also exerted its impact on the adjacent eco-environment, both directly and indirectly (Figure 9c). 


\section{Discussion}

The disorderly competition for natural resources and the continued deterioration of the fragile environment may result in the amplification of risks posed to Central Asia (Tookey, 2007). Conflicts between the fragile eco-environment and high-resource-consuming urbanization were observed in all five countries, but considering the differences among them in terms of water and land resources, they were confronted with varying degrees of risk. A close relevance was noted in these relationships across country.

(1) Temporal conductivity

Driving factors are different in the three historic stages of urbanization in Central Asia, while the consequences of the former stage may exert influence on the later stages, which was defined as temporal conductivity. Before colonization by Russia, most nations in Central Asia were khanates and the pace of urbanization was slow. From the Russian colonization to the advent of the Soviet Union, passive rapid urbanization in the context of the specific historical background of the region led to massive stress on resources and the environment, the effects of which persist to today. Under Russian colonization and in the Soviet era, the cotton production base in Central Asia supported the industrialization of the Soviet Union at the cost of the consumption of large amounts of freshwater. The mining of mineral resources promoted urbanization but also led to serious pollution. Immigrants further accelerated urbanization, and this contributed to such problems as changes in the grassland ecology and hydrological patterns. The accelerated industrialization owing to military-related demand in the Soviet period led to the imposition of an unreasonable industrial structure and yielded inefficient economic development (Batsaikhan et al., 2017), leading to a sharpening of the tensions between rapid urbanization and the fragile eco-environment. Low-level industrialization brought about the dilemma of a severely destroyed eco-environment and a lack of motivation for urbanization. For urbanization in arid regions, such measures as the concentration of the population, and efficient and intensive use of resources should have been taken to relieve the stress on the eco-environment. The absence of a sound structure for the industrial system led to the failure of resource-intensive utilization. Only by changing these long-standing problems can endogenous motivation for urbanization be provided in the future. This problem in human-land relationship systems - namely, urbanization-related activities — should be studied to protect the resource environment (Yang et al., 2019).

(2) Spatial relevance

The five countries of the region are connected through transnational water systems. Accordingly, the relationship between urbanization and the resource environment have close spatial relevance. It is difficult to resolve the Aral Sea crisis in the current complex international situation. Cities and towns around the Aral Sea are thus declining, and this is affecting the surrounding eco-system. In addition, the traditional means of agricultural development have not yet been upgraded. These factors will lead to further ecological degradation downstream of the Amu Darya and influence urbanization at a larger spatial scale than before. Interestingly, the intensive human activity that has caused the crisis can also be a potential driver to save the Aral Sea (White K D, 2013).

Water conflicts in local and transboundary regions may worsen in the coming decades owing to the increasing demand for freshwater (Groll et al., 2015). Considering the increas- 
ing risks to external ecological security due to urbanization, it is necessary to optimize the resources and environmental relations within cities, and to establish and implement coordination mechanisms and strategies for transnational water resources.

(3) Theoretical contribution and methodological shortcomings

Compared with the literature on urbanization and the resource environment in arid areas, the theoretical contribution of this paper lies in the construction of a model to explain the spatio-temporal conductivity in the dynamic evolution between urbanization, and resources and the environment. In Central Asia, a typical arid area, the impact of urbanization in different historical stages on the resource environment has continued to the present, and the problems related to resources and the environment in local areas are spreading. It is thus important to model this process to understand the complexity of human-environment interaction in this fragile eco-environment area.

There is still much work to be done in the future. It was challenging to obtain data on resources, especially water resources, in these countries. More accurate data are needed to build quantitative model to interpret the relationship between urbanization and resource environment in Central Asia.

\section{Conclusions}

Based on an analysis of the mechanism of interaction between urbanization and the resource environment in Central Asia, this study yielded the following main conclusions:

(1) In different periods, the interactions between urbanization and the resource environment were different. During Russian colonization, urbanization led to significant land conflicts. About 49.05 million ha of land was confiscated by Cossack colonizers in 1917 and used to construct fortresses, towns, and roads. During passive urbanization in the Soviet Union, the rate of urbanization of the population in Central Asia increased from $17 \%$ in 1930 to $45.3 \%$ in 1985 , and resources and the environment deteriorated. After the fall of the Soviet Union in 1991, the newly independent countries of the region faced numerous problems related to water, land, and the ecology.

(2) The eco-environment of upstream countries in the Syr Darya and Amu Darya basins is relatively stable while resource constraints are notable in downstream countries. The spread of urban land use was significant, and the mode number of urban land compactness decreased from 0.44 in 1990 to 0.31 in 2015, indicating the low level of intensity of land use. The efficiency of utilization of water for urbanization, industrialization, and agricultural development was low, and problems related to water shortage are becoming increasingly serious.

(3) We analyzed the interaction between urbanization and the resource environment in Central Asia in three stages. In the early stage of urbanization, a small number of cities and towns were distributed mainly in oases, adjacent to water sources, and had no significant impact on the eco-environment. During passive urbanization, this distribution extended into deserts, adjacent to water bodies and mineral resources, and occupied a large area of grassland. In this stage, conflicts between urbanization and the available land, and water and the environment began to appear. In the active improvement stage of urbanization, motivations for urbanization differed among countries of the region. Some cities and towns maintained 
the trend of developing while others decayed. Low-level urbanization led to issues related to the abuse of water and land as well as the pollution of the eco-environment. Transnational conflicts for water also threatened the urbanization in the downstream countries.

\section{References}

Abuduwaili J, Ma L, 2015. Overview of Central Asian Environments. Beijing: China Meteorological Press, 237. (in Chinese)

Adle C, 2017. History of Civilizations of Central Asia •VI (First). Beijing: Chinese Translation Press, 20-41. (in Chinese)

Bao C, Fang C L, 2007. Water resources constraint force on urbanization in water deficient regions: A case study of the Hexi Corridor, arid area of NW China. Ecological Economics, 62(3): 508-517.

Batsaikhan U, Marek D, 2017. Central Asia: Twenty-five years after the breakup of the USSR. Russian Journal of Economics, 3(3): 296-320.

Chen X, Jiang F Q, Wang Y J et al., 2013. Characteristics of the eco-geographical pattern in arid land of Central Asia. Arid Zone Research, 30(3): 385-390. (in Chinese)

Chen Y N, Li B F, Li Z et al., 2016. Water resource formation and conversion and water security in arid region of Northwest China. Journal of Geographical Sciences, 26(7): 939-952.

Cui X G, Fang C L, Liu H M et al., 2019. Assessing sustainability of urbanization by a coordinated development index for an Urbanization-Resources-Environment complex system: A case study of Jing-Jin-Ji region, China. Ecological Indicators, 96: 383-391.

Daniel K, 2018. Environmental changes in Central and East Asian drylands and their effects on major river-lake systems. Quaternary International, 475: 91-100.

Deng M J, Long A H, Zhang Y et al., 2010. Assessment of water resources development and utilization in the five Central Asia countries. Advances in Earth Science, 25(12): 1347-1356. (in Chinese)

Fang C L, 2003. Hexi Corridor: Oasis supports urbanization! Discussion with Mr. Zhong Weizhi. Journal of Desert Research, 23(3): 128-130. (in Chinese)

Fang C L, Cui X G, Li G D et al., 2019. Modeling regional sustainable development scenarios using the urbanization and eco-environment coupler: Case study of Beijing-Tianjin-Hebei urban agglomeration, China. Science of the Total Environment, 689: 820-831.

Groll M, Opp C, Kulmatov R et al., 2015. Water quality, potential conflicts and solutions: An upstream-downstream analysis of the transnational Zarafshan River (Tajikistan, Uzbekistan). Environmental Earth Sciences, 73(2): 743-763.

He Q, 2016. Investigation on Climate Change in Central Asia. Beijing: China Meteorological Press, 1-6. (in Chinese)

Hu R J, Jiang F Q, Wang Y J et al., 2014. Central Asia (five countries) arid ecological geographical and environmental characteristics. Arid Zone Research, 31(1): 1-12. (in Chinese)

Hu W J, Liu H L, Bao A M et al., 2018. Influences of environmental changes on water storage variations in Central Asia. Journal of Geographical Sciences, 28(7): 985-1000.

Institute of History of the Soviet Academy of Sciences (IHSAS), 1997. The History of the Soviet Nation-State Construction (Volume II). Beijing: The Commercial Press, 511-525. (in Chinese)

Li J L, Bao A M, Chen W et al., 2017. Stressed Resources and Environment in the Context of Climate Change. Beijing: China Meteorological Press, 186. (in Chinese)

Li J X, Chen Y N, Xu C C et al., 2019. Evaluation and analysis of ecological security in arid areas of Central Asia based on the emergy ecological footprint (EEF) model. Journal of Cleaner Production, 235: 664-677.

Lioubimtseva E, Henebry G M, 2009. Climate and environmental change in arid Central Asia: Impacts, vulnerability, and adaptations. Journal of Arid Environments, 73(11): 963-977. 
Liu H M, Fang C L, Fang K, 2020. Coupled Human and Natural Cube: A novel framework for analyzing the multiple interactions between humans and nature. Journal of Geographical Sciences, 30(3): 355-377. (in Chinese)

Ma H T, Liu H M, Zhang F F, 2018. A review on relationships between urbanization and eco-environment in different spatial scales. World Regional Studies, 27(5): 60-70. (in Chinese)

Panov B T, 1985. Soviet Encyclopedia. Moscow: Moscow Press, 113. (in Russian)

Qiao B, Fang C L, Li M, 2005. The dynamic coupling model of the harmonious development between urbanization and eco-environment and its application in arid area. Acta Ecologica Sinica, 25(11): 3003-3009. (in Chinese)

Shi B, 2009. A brief analysis of water resources crisis and cooperation in Central Asia: The transformation from Neorealism to Neoliberal perspective. Russian Central Asian \& East European Market, (1): 25-29. (in Chinese)

Tookey D L, 2007. The environment, security and regional cooperation in Central Asia. Communist and Post-Communist Studies, 40(2): 191-208.

White K D, 2013. Nature-society linkages in the Aral Sea region. Journal of Eurasian Studies, 4(1): 18-33.

Xie J, Zhang Y, Li F et al., 2017. Kazakhstan: Environmental governance starts from industrial sources. China Environment News, http:/epaper.cenews.com.cn/html/2017-10/19/content_66130.htm, 2017-10-19. (in Chinese)

Yang S T, Yu X Y, Ding J L et al., 2017. A review of water issues research in Central Asia. Acta Geographica Sinica, 72(1): 79-93. (in Chinese)

Yang Y, Li X Y, Dong W et al., 2019. Assessing China’s human-environment relationship. Journal of Geographical Sciences, 29(8): 1261-1282.

Yang Y, Liu Y, 2014. Spatio-temporal analysis of urbanization and land and water resources efficiency of oasis cities in Tarim River Basin. Journal of Geographical Sciences, 24(3): 509-525.

Yao H J, Zhou H F, Su F C, 2013. Water problems based on spatial matching patterns of water and land resources in central Asia. Arid Zone Research, 30(3): 391-395. (in Chinese)

Yeerken W, 2015. Pattern, process and mechanism of Central Asia's urbanization during 1992-2012 [D]. Beijing: University of Chinese Academy of Sciences, 86. (in Chinese)

Zhang Y, 2005. Water resources in Central Asia. Central Asian Information, (10): 11-15. (in Chinese)

Zhang Y M, Li Y M, Sha G M, 2013. Plant Resources and Utilization in Central Asia. Beijing: China Meteorological Press, 3. (in Chinese)

Zhu H Y, Li X B, 2003. Discussion on the model methodology of regional land use change index. Acta Geographica Sinica, 58(5): 643-650. (in Chinese) 